\title{
Characteristics of Inclusion Motion and Accumulation in CSP Mold
}

\author{
Changping NIE, ${ }^{1)}$ Xiaofeng ZHANG, ${ }^{1)}$ Bao WANG,${ }^{1)}$ Yuhu SUN ${ }^{2)}$ and Qing LIU ${ }^{1 / *}$ \\ 1) State Key Laboratory of Advanced Metallurgy, University of Science and Technology Beijing, Haidian District, Beijing, 100083

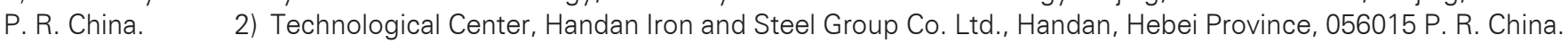

(Received on February 2, 2015; accepted on April 16, 2015)

\begin{abstract}
The accumulation of inclusions in the initial solidified shell, which may cause longitudinal cracks, is studied in this paper. The composition, morphology and distribution of large inclusions in thin slab are investigated by inclusion measurements. Based on the experiment, the quantity and size distribution of inclusions are obtained as reference in predicting inclusion behavior in CSP mold through numerical simulation. Due to the funnel-shaped structure of mold, inclusions injected through SEN are mostly captured by the solidifying shell in the funnel region nearby the parallel part of mold, which cause the accumulation of inclusions in thin slab within this region. Moreover, the simulation results are consistent with experimental data that large inclusions concentrate at the position of $1 / 4$ slab width, which suggests a lower product quality there. In addition, the distribution of inclusions in the solidified shell is closely related to their motion in the mold. Specifically, the transport and removal of inclusions entrained from mold slag are calculated, since K/Na-contained inclusions and excessive surface velocity demonstrate that slag entrainment appears in CSP mold. These inclusions can float up easily, while those entrapped by the shell are detrimental to thin slab quality.
\end{abstract}

KEY WORDS: CSP mold; thin slab; inclusions; mold slag entrainment; numerical simulation.

\section{Introduction}

The longitudinal crack is one of the most severe quality defects in thin slabs. Factors affecting the formation of longitudinal cracks on the shell are complex, particularly in the compact strip production (CSP) process. Due to the characteristics of CSP mold shape, thin slab is prone to longitudinal surface cracks. ${ }^{1)}$ Ramacciotti et al. ${ }^{2)}$ found that solidifying shell in the transition region between funnel and parallel part of the funnel-shaped mold bore larger stress than that in other areas. Sun et al. ${ }^{3)}$ also observed that longitudinal surface cracks mainly appeared in the $1 / 4$ region of the broad face. Zhang et al. $^{4)}$ reported that the temperature gradient on the slab broad face near the large deformation zone of mold was great, which might be the reason for slab longitudinal cracks. Besides, according to references, $\left.{ }^{5,6}\right)$ the accumulation of non-metallic inclusions in the initial solidified shell can also lead to the drop of stress resistance ability of shell, which finally causes longitudinal cracks on slab surface. And the final distribution of inclusions in slab is closely related to their motion in the mold. Therefore, this article attempts to investigate the effects of inclusion accumulation in thin slab on the occurrence of longitudinal cracks by studying the inclusion behavior in CSP mold.

During the continuous casting process, jets of molten steel exiting the submerged entry nozzle (SEN) ports carry

\footnotetext{
* Corresponding author: E-mail: qliu@ustb.edu.cn

DOI: http://dx.doi.org/10.2355/isijinternational.ISIJINT-2015-063
}

inclusion particles into the mold. In addition, droplets of liquid mold slag may be entrained into the molten steel due to excessive surface velocity and level fluctuation. ${ }^{7)}$ Inclusion particles from the both sources can either float up or be entrapped in the solidifying shell. Many researchers ${ }^{8-12)}$ have developed various mathematical models to investigate inclusion transport in the mold. However, most of these studies focused only on the conventional slab/billet mold with regularly shaped geometry. Little work has been done on the coupled modeling of fluid flow, solidification and inclusion motion in a complex-shaped CSP mold.

In this paper, inclusion measurements are carried out on CSP thin slab to analyze the morphology, composition and size distribution of large inclusions. Then, based on the composition, size and quantity of large inclusions obtained by inclusion measurements, the motion of inclusions injected from SEN and slag entrainment in CSP mold are mathematically investigated. And the distribution of inclusions in thin slab and the removal fraction of inclusions are studied.

\section{Research Methods}

This work is carried out based on the combination of experimental measurements and numerical analysis. Since it is difficult and costly to analyze the steel cleanness under different operating conditions only by inclusion measurements, mathematical model is adopted as a useful tool. The quantity and size distribution of inclusions obtained 
by inclusion measurements are used for numerical analysis. And the motion of inclusions in CSP mold predicted by numerical simulation is closely related to the distribution of inclusions in thin slab.

\subsection{Inclusion Measurements}

The experiment is carried out on Low Carbon Al-killed steel (LCAK steel) CSP thin slab at No.3 steelmaking plants in Handan Steel, Hebei Iron and Steel Group Co. Ltd., P. R. China. The CSP process at Handan Steel includes BOF steelmaking, LF refining and CSP thin slab casting. In the actual production, longitudinal surface cracks are found in the thin slab.

The schematic of slab sampling is illustrated in Fig. 1. Steel samples were taken from three different positions in the slab: the center, the quarter and the edge of thin slab. Each sample is $50 \mathrm{~mm}$ in width, $50 \mathrm{~mm}$ in thickness and $150 \mathrm{~mm}$ in length. The experimental analysis includes slime electrolytic extraction ${ }^{6}$ for large nonmetallic inclusions (> $50 \mu \mathrm{m}$ in diameter), SEM analysis for the morphology and composition of inclusions. In the slime electrolytic extraction experiment, a relatively large steel sample (about $2 \mathrm{~kg}$ ) is immersed in a mixed solution of $\mathrm{FeCl}_{2}$ and $\mathrm{FeSO}_{4}$. The sample is almost completely dissolved by applying electric current through it, and the remained nonmetallic inclusions are collected and graded for counting and further analysis.

\subsection{Numerical Analysis}

The standard $k-\varepsilon$ turbulence model is chosen to describe

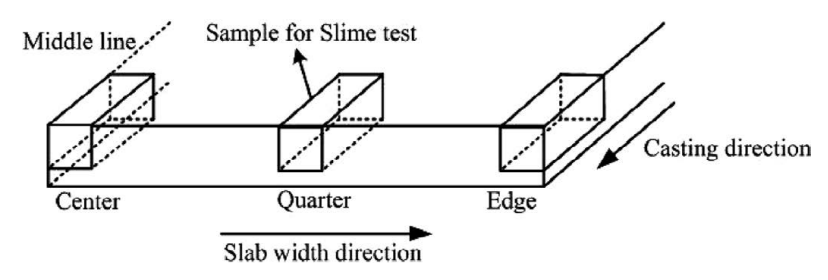

Fig. 1. Sampling positions in CSP thin slab.

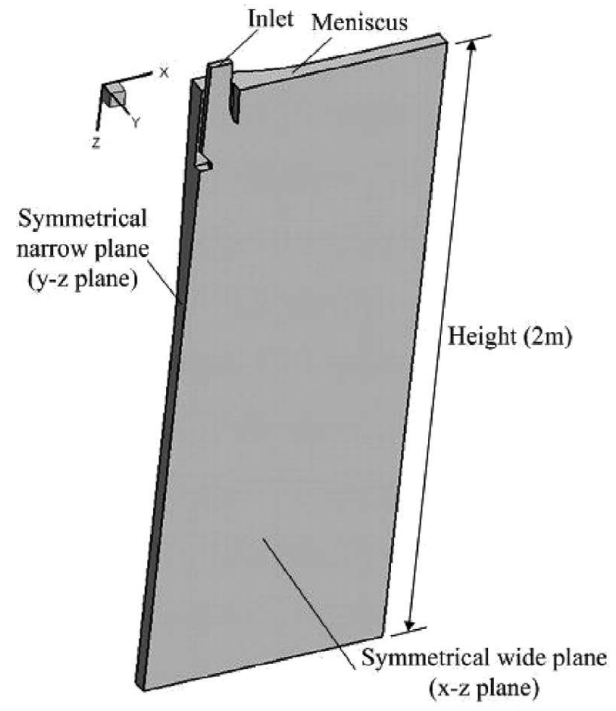

(a) the single-phase steady flow in the mold. The enthalpyporosity model is adopted to simulate the solidification process of molten steel. More details are available elsewhere. ${ }^{8,13)}$

Due to the low volume fraction of inclusion particles, the uncoupled Lagrangian discrete phase model (DPM) is always applied to calculate the trajectory of particles. The motion of particles can be simulated by integrating the following equations for each particle:

$$
\frac{d x_{p}}{d t}=u_{p}
$$

$$
\frac{d u_{p i}}{d t}=\frac{18 \mu}{\rho_{p} d_{p}^{2}} \frac{C_{D} R e_{p}}{24}\left(u_{i}-u_{p i}\right)+\frac{\rho_{p}-\rho}{\rho_{p}} g_{i}+F_{i}
$$

where $x_{p}$ is the particle position, $t$ is the time (s), $\mu$ is the viscosity of fluid $(\mathrm{kg} / \mathrm{m} \cdot \mathrm{s}), u_{i}$ and $u_{p i}$ are the velocities of fluid and particle at direction $i(\mathrm{~m} / \mathrm{s})$, respectively, $d_{p}$ is the particle diameter $(\mathrm{m}), \rho_{p}$ and $\rho$ are the densities of particle and fluid, respectively, $C_{D}$ is the drag coefficient, $R e_{p}$ is particle Reynolds number, and $g_{i}$ is the gravitational acceleration rate $\left(\mathrm{m} / \mathrm{s}^{2}\right)$. The three terms on the right-hand side are the drag force (always opposite to the motion direct) per unit of particle mass, the buoyancy force (due to the density difference) and the additional forces $\left(F_{i}\right)$, respectively. To incorporate the chaotic effect of turbulent fluctuations on inclusion motion, the "random walk" model is employed. In this model, the velocity fluctuations of fluid obey a Gaussian probability distribution. The instantaneous fluid velocity is then given by

$$
\begin{array}{r}
u=\bar{u}+u^{\prime} \ldots \ldots \ldots \\
u^{\prime}=\xi \sqrt{\overline{u^{\prime 2}}}=\xi \sqrt{2 k / 3}
\end{array}
$$

where $u$ is the instantaneous fluid velocity $(\mathrm{m} / \mathrm{s}), \bar{u}$ is the mean fluid phase velocity $(\mathrm{m} / \mathrm{s}), u^{\prime}$ is the random velocity fluctuation $(\mathrm{m} / \mathrm{s}), \xi$ is a random number, and $k$ is the local

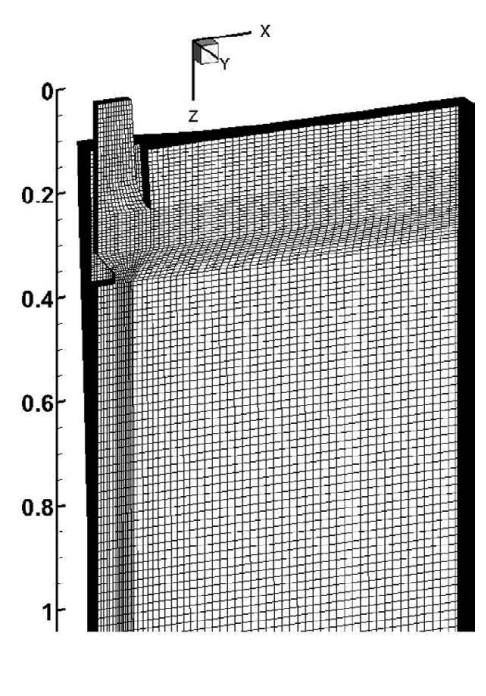

Fig. 2. Schematics of mold geometry (a) and mesh system (b). 
turbulent kinetic energy $\left(\mathrm{m}^{2} / \mathrm{s}^{2}\right)$.

The geometry and mesh system are shown in Fig. 2. The sizes of the first grid next to the wall are less than $2 \mathrm{~mm}$ and then increase gradually at a rate of 1.3. In order to reduce the impacts of backflow at the outlet on simulation results, the calculation domain is extended to $2 \mathrm{~m}$. The main dimensions and parameters are listed in Table $\mathbf{1 .}$

Inclusion particles are assumed to be spherical and introduced into the computational domain at the local fluid velocity. It is assumed that inclusions escape once touching the top surface or entering the bottom of the domain, and are entrapped when contacting the solidifying shell with the liquid fraction below 0.6. ${ }^{14)}$ Specifically, the amount of simulated inclusions is determined by experimental data rather than that assumed in previous studies. ${ }^{2-7)}$ Firstly, the exact number of large inclusions in each sample was determined by SEM analysis. Then, the total amount of different-sized inclusions that enter the two-meter-long calculation domain can be calculated by Eq. (5). And the results are shown in Fig. 3. In Fig. 3, the inclusion sizes are classified into five levels, and the size of nearly half inclusions in the molten steel is between $75 \mu \mathrm{m}$ and $120 \mu \mathrm{m}$. Meanwhile, for the convenience of simulation, these inclusions are assumed to be equivalent to $50 \mu \mathrm{m}, 100 \mu \mathrm{m}, 150 \mu \mathrm{m}, 200 \mu \mathrm{m}$ and $250 \mu \mathrm{m}$, respectively.

$$
N_{\mathrm{i}}=\mathrm{n}_{i} \frac{V_{\text {slab }}}{V_{\text {sample }}}
$$

where $i$ represents the inclusions in one size range, $N_{i}$ is the total amount of inclusion $i$ in thin slab, $\mathrm{n}_{i}$ is the exact average number of large inclusion $i$ in one slab sample, $V_{\text {slab }}$ and $V_{\text {sample }}$ are the volume of thin slab and slab sample, respectively. Since the removal fraction of inclusion particles in CSP mold is very low (which is presented in this paper), the amount of removed inclusions can be neglected for the calculation in Eq. (5).

\section{Results and Discussions}

\subsection{Results of Inclusion Measurements}

The morphology and components of typical inclusions in slab samples are shown in Table 2 ( $a, b, c$ and d represent different types of inclusions). It can be seen that most of the nonmetallic inclusions are spherical except some irregularly
Table 1. Main dimensions and physical parameters for simulation.

\begin{tabular}{lc}
\hline \multicolumn{1}{c}{ Parameter } & Value \\
\hline Mold cross section $(\mathrm{mm})$ & $1500 \times 90$ \\
Effective mold length $(\mathrm{mm})$ & 1000 \\
Height of the funnel-shaped region $(\mathrm{mm})$ & 850 \\
SEN submerged depth ${ }^{[1]}(\mathrm{mm})$ & 250 \\
Jet flow angle $\left(^{\circ}\right)$ & 40 (downward) \\
Casting speed $(\mathrm{m} / \mathrm{min})$ & 5 \\
Density of liquid steel $\left(\mathrm{kg} / \mathrm{m}^{3}\right)$ & 7020 \\
Viscosity of liquid steel $(\mathrm{kg} / \mathrm{m} \cdot \mathrm{s})$ & 0.0055 \\
Specific heat of liquid steel $(\mathrm{J} / \mathrm{kg} \cdot \mathrm{K})$ & 720 \\
Thermal conductivity of liquid steel $(\mathrm{W} / \mathrm{m} \cdot \mathrm{K})$ & 27 \\
Thermal conductivity of solid steel $(\mathrm{W} / \mathrm{m} \cdot \mathrm{K})$ & 30 \\
Casting temperature $(\mathrm{K})$ & 1820 \\
Liquids temperature $(\mathrm{K})$ & 1794 \\
Solids temperature $(\mathrm{K})$ & 1749 \\
Latent heat of fusion $(\mathrm{J} / \mathrm{kg})$ & 272000
\end{tabular}

Note: [1] Defined as the distance from the bottom of SEN to the meniscus of mold.

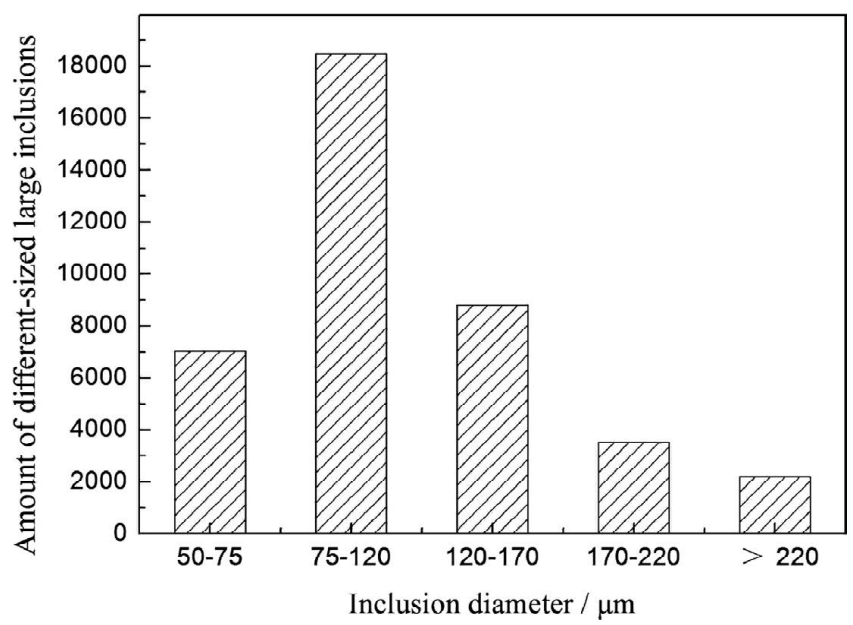

Fig. 3. Predicted total amount of different-sized large inclusions in the molten steel within the two-meter-long calculation domain.

Table 2. Typical inclusions extracted by the slime method.
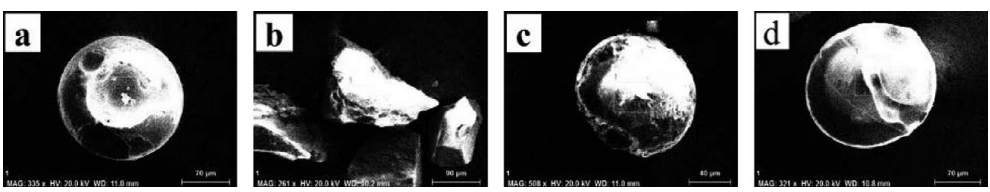

\begin{tabular}{ccccccccccccc}
\hline \multicolumn{10}{c}{ Atomic percent/\% } \\
\hline & $\mathrm{C}$ & $\mathrm{O}$ & $\mathrm{Mg}$ & $\mathrm{Al}$ & $\mathrm{Si}$ & $\mathrm{Ca}$ & $\mathrm{Fe}$ & $\mathrm{S}$ & $\mathrm{K}$ & $\mathrm{Tb}$ \\
\hline $\mathrm{a}$ & - & 35.93 & 7.01 & 23.48 & - & 25.95 & 6.20 & 0.10 & - & 1.33 \\
$\mathrm{~b}$ & 21.34 & 54.08 & - & 5.18 & 13.00 & - & 4.92 & - & 0.58 & 0.91 \\
$\mathrm{c}$ & 22.98 & 44.27 & 5.55 & 16.86 & - & 0.68 & 7.49 & 0.67 & - & 1.51 \\
$\mathrm{~d}$ & 19.56 & 52.33 & 0.87 & 14.62 & 0.46 & 8.70 & 2.92 & 0.55 & - & - \\
\hline
\end{tabular}


shaped inclusions. The chemical compositions of large inclusions are mainly oxide inclusions, such as $\mathrm{Al}_{2} \mathrm{O}_{3}, \mathrm{MgO}$, $\mathrm{CaO}$ and $\mathrm{SiO}_{2}$. According to the inclusion composition, the possible resources of these large inclusions are reoxidation products and erosion of lining refractory. Furthermore, some of these inclusions contain $\mathrm{K}$ and $\mathrm{Na}$, indicating that they may be induced from mold slag entrainment. Generally, slag entrainment arises from excessive level fluctuation which will be discussed later in this paper.

Figure 4 presents the weight of large inclusions per $10 \mathrm{~kg}$ steel in different size range and along the slab width direction. The result shows that inclusions in the range of $140 \mu \mathrm{m}$ to $300 \mu \mathrm{m}$ are heaviest in weight, which is $0.53 \mathrm{mg} / 10 \mathrm{~kg}$ steel for heat 1 and $0.63 \mathrm{mg} / 10 \mathrm{~kg}$ steel for heat 2, respectively. Figure 4(b) indicates that the content of large inclusions at the position of $1 / 4$ slab width, which is over $40 \%$, is more than that in other positions. The distribution of inclusions in thin slab is closely related to inclusion behavior in the mold which is significantly affected by fluid flow during the solidification process.

\subsection{Fluid Flow and Solidification in CSP Mold}

Figure 5 shows the characteristics of fluid flow in CSP mold. The jet discharging from the SEN ports traverses across the molten pool and impinges the narrow face to split into two parts, forming a classical double-roll recirculating flow pattern. As the solidification progresses, the liquid pool space becomes narrow and the flow in the mushy zone is weakened, which results in rapid dissipation of turbulent intensity of steel jet in its propagation process. Generally, this predicted flow characteristics in the mold are in agreement with the observed results of water model performed by Torres-Alonso et al., ${ }^{15)}$ which can be applied to validate the present model to some extent.

Figure 6 presents the velocity distribution and level profile on the centerline of top surface. The top surface profile has a great impact on slag entrainment and strand surface quality. The level profile is expressed by the liquid displacement that is estimated from a simple potential energy balance. ${ }^{3)}$ It can be seen that the maximum amplitude of level fluctuation is $7.2 \mathrm{~mm}$ and the maximum surface velocity is

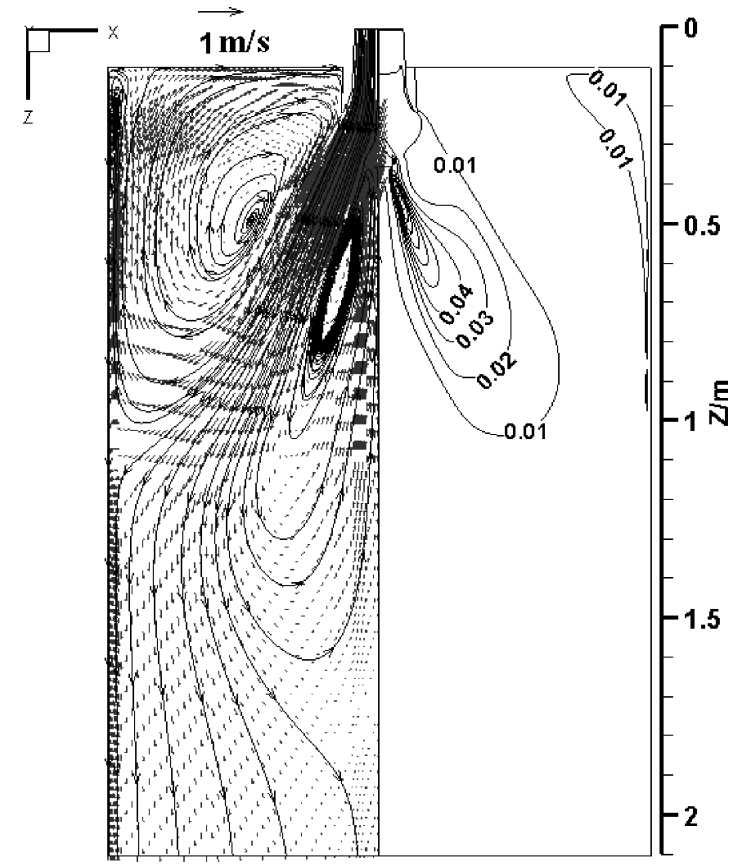

Fig. 5. Velocity vector (left) and turbulent kinetic energy (right) distribution in the $\mathrm{x}-\mathrm{z}$ center plane.

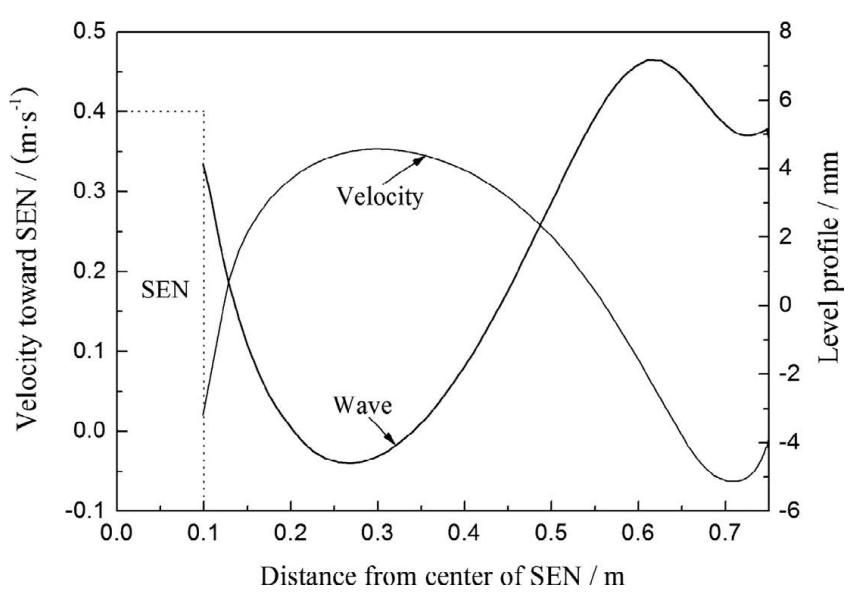

Fig. 6. Velocity distribution and level profile on the centerline of top surface.

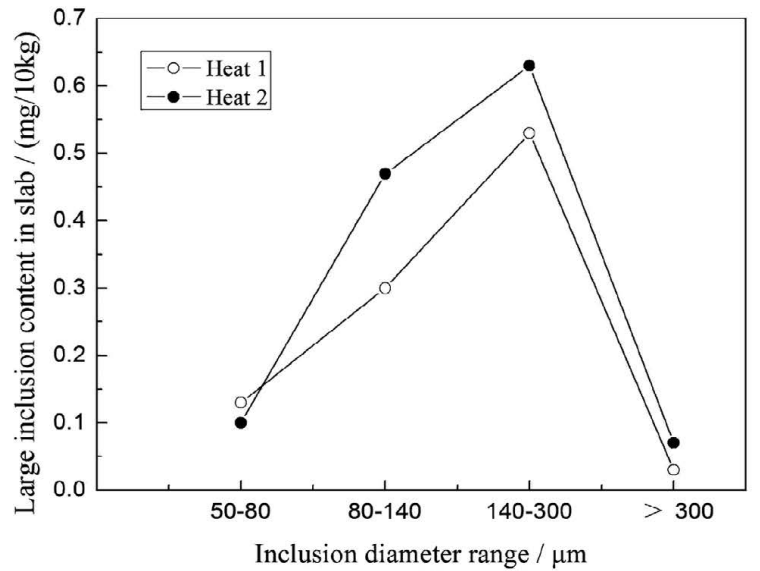

(a)

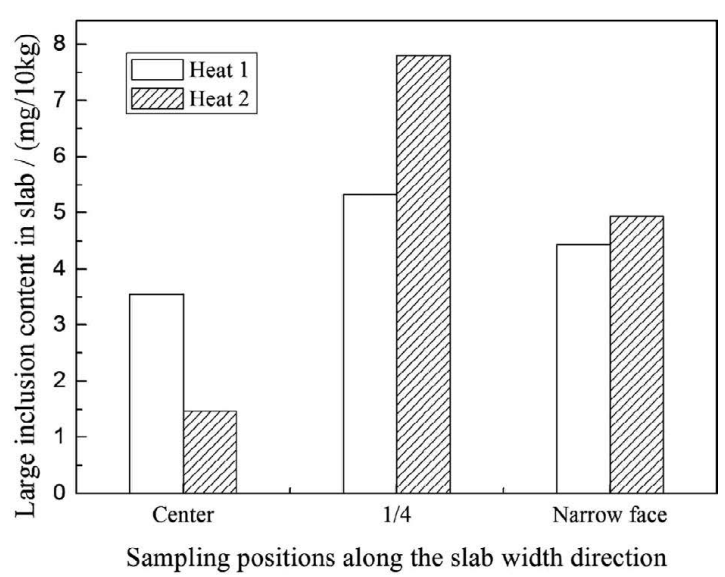

(b)

Fig. 4. The distribution of large inclusion content in different size range (a) and along the slab width direction (b) (The casting temperature of heat 1 and heat 2 is $1817 \mathrm{~K}$ and $1823 \mathrm{~K}$, respectively). 
$0.35 \mathrm{~m} / \mathrm{s}$. According to Zhang et al., ${ }^{16)}$ the surface velocity should be kept below $0.3 \mathrm{~m} / \mathrm{s}$ or $0.4 \mathrm{~m} / \mathrm{s}$ and above $0.1 \mathrm{~m} / \mathrm{s}$ or $0.2 \mathrm{~m} / \mathrm{s}$ to decrease mold slag entrainment and meniscus freezing. Therefore, in this case, slag entrainment is likely to happen.

Figure 7 reveals the predicted growth of solidified shell. The shell thickness on the center line of broad face and narrow face at mold exit are $9.8 \mathrm{~mm}$ and $9.0 \mathrm{~mm}$, respectively. The shell thickness is not always increasing as the slab is pulled forward. It can be seen that, a slight drop of shell thickness on the center line of broad face occurs in the range of $0.69 \mathrm{~m}$ to $0.74 \mathrm{~m}$ below the meniscus, which happens to be located in the region at the edge of the funnel shape of mold. The reason may be that the solidifying shell in this region suffers strong washing of molten steel flow, which leads to the remelting of shell.

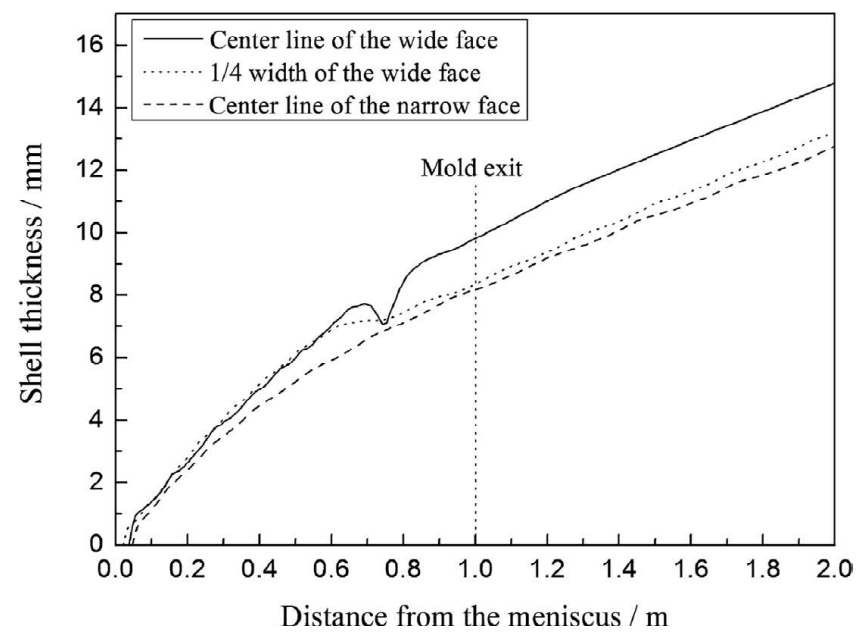

Fig. 7. The growth of solidified shell.

\subsection{Transport of Inclusions Injected through SEN}

Based on the size distribution and amount of inclusions analyzed by inclusion measurements, the transport of inclusions ranging in size from $5 \mu \mathrm{m}$ to $300 \mu \mathrm{m}$ injected randomly at SEN inlet, was investigated. Three typical snapshots of particle $(50 \mu \mathrm{m})$ distribution at different time after the first injection are presented in Fig. 8. The red dots represent moving inclusion particles, and the captured or removed ones are displayed in blue color. As can be seen in Fig. 8, the inclusions move with the high-intensity jet flow and are first captured by the solidifying shell in the funnel region nearby the parallel part of the mold, where is also the place most of inclusion entrapment occurs. Therefore, inclusion accumulation is most likely to occur in this region of thin slab. And this result is mainly attributed to the funnelshaped structure of CSP mold.

Nine seconds later after the first injection (Fig. 8(c)), the inclusion particles are dispersed throughout the domain. Those inclusions which escape from the bottom region of calculation domain are trapped deeply in the thin slab.

Figure 9 shows the removal fraction of inclusions in different sizes from the top surface of mold. The removal fraction increases with increasing inclusion diameter, from $2.18 \%$ for $5-\mu \mathrm{m}$ inclusions to $3.67 \%$ for $300-\mu \mathrm{m}$ inclusions. This result is expected since the buoyancy force acting on large inclusions is larger than that on small ones. The buoyancy force contributes to the floating of inclusions. However, the overall removal fraction is low. Because the residence time of inclusions is short owing to the high casting speed, there is no enough time for inclusions to float up. Moreover, inclusion particles of $100 \mu \mathrm{m}$ to $300 \mu \mathrm{m}$ are large enough to cause severe quality problems, yet are predicted to have high entrapment fractions. Therefore, it is important to remove these inclusions before casting.

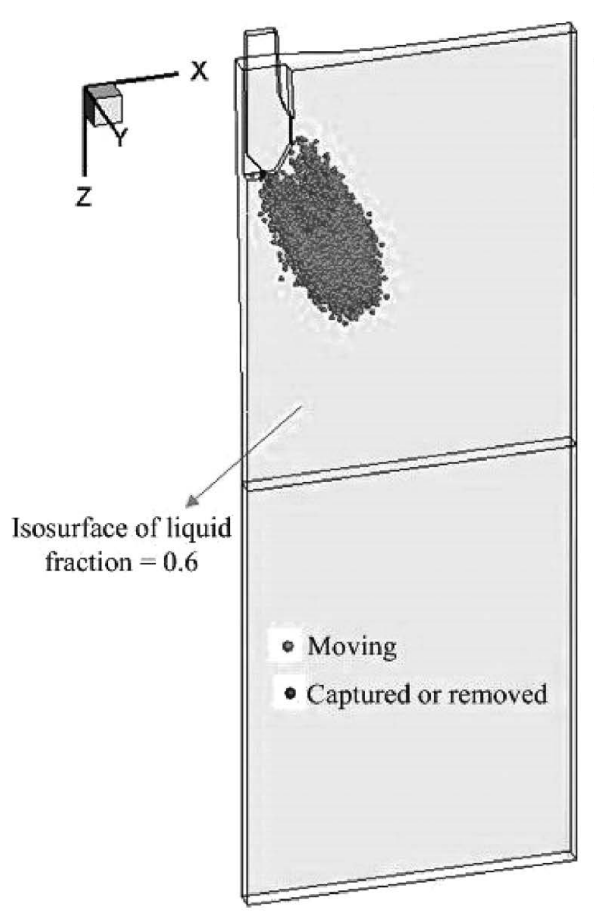

(a) Tracking time $=0.5 \mathrm{~s}$

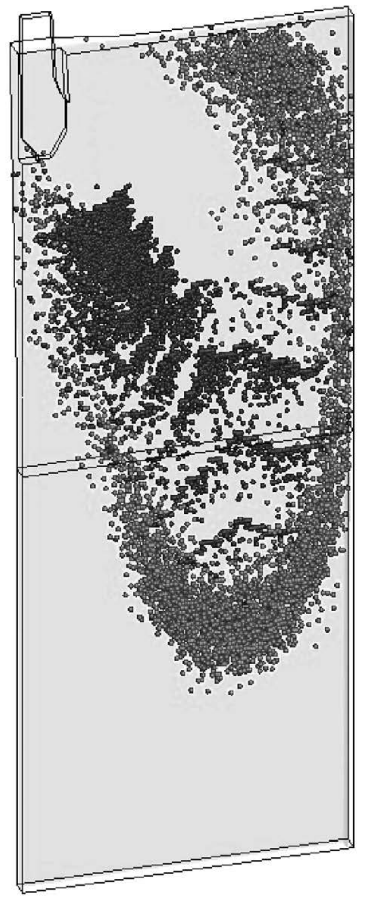

(b) Tracking time $=4 \mathrm{~s}$

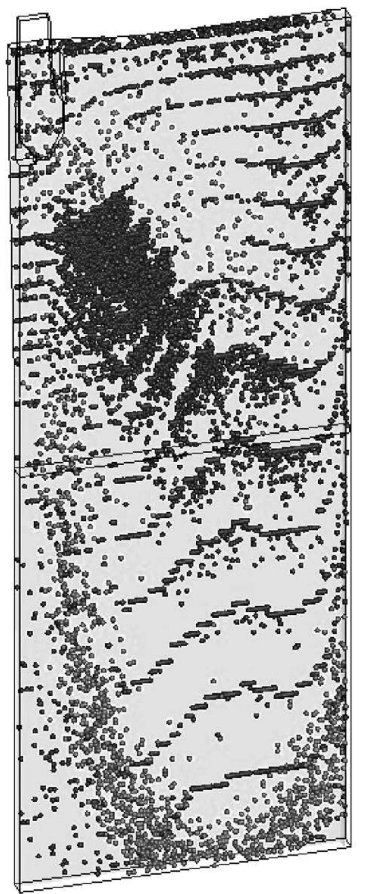

(c) Tracking time $=9 \mathrm{~s}$

Fig. 8. Calculated distributions of $50-\mu \mathrm{m}$ inclusion particles injected through SEN. 
By projecting the entrapment positions in the entire computational domain onto a transverse $x-y$ section, the distribution of $100-\mu \mathrm{m}$ inclusions in the cross section of strand is calculated, as shown in Fig. 10. The solid curve represents the solidifying front at the domain exit $(2 \mathrm{~m}$ below the meniscus). It can be seen that the captured inclusions within the solidified shell are unevenly distributed. The inclusions are concentrated approximately $5 \mathrm{~mm}$ to $10 \mathrm{~mm}$ beneath the slab surface, while the distribution of inclusion content along the slab width direction is shown more clearly in Fig. 11.

Figure 11 shows the distribution of inclusion content along the slab width direction obtained by numerical simulation and inclusion measurements. The predicted relative mass percentage $\left(I_{p, i}\right)$ of entrapped inclusions by numerical simulation can be calculated by Eq. (6).

$$
I_{p, i}=\frac{m_{p, i}}{\sum_{i=0}^{n} m_{p, i}} \%
$$

where $m_{p, i}$ is the mass of inclusions entrapped in thin slab at a specific position $i$ (i.e. the center, quarter and edge of thin slab), $n$ is the number of positions for the comparison.

As can be seen in Fig. 11, the distribution tendency of inclusion content obtained by simulation is similar to the experimental results. More large inclusions gather at the position of $1 / 4$ slab width and less inclusions stay in the slab center, which is consistent with the earlier results (as shown in Figs. 4 and 8).

It is well-known that large inclusions are very harmful to mechanical properties of thin slab and the inclusion accumulation in slab may cause longitudinal cracks. Combined Figs. 8 and 11, it can clearly reveal that inclusion behavior in CSP mold has a great effect on the distribution of inclu-

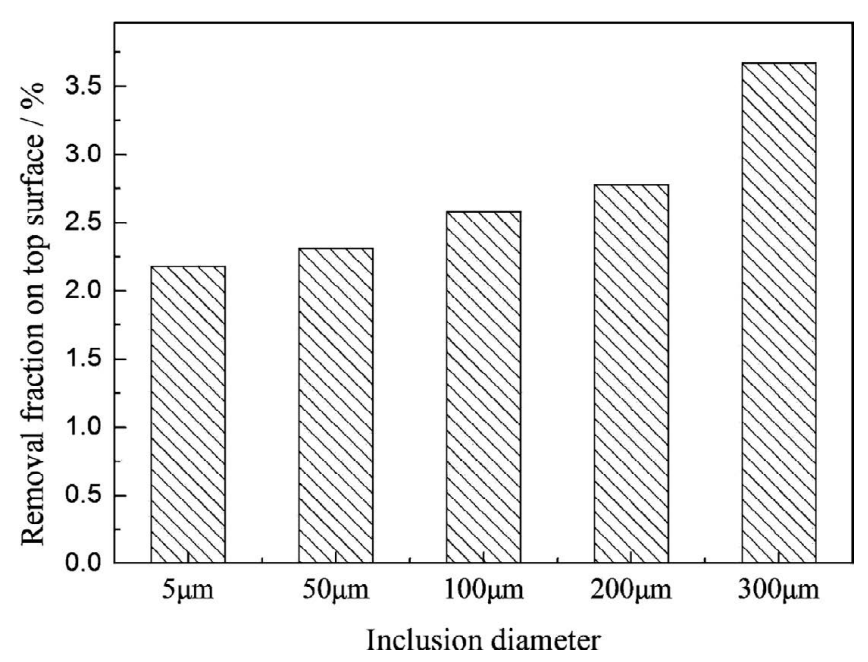

Fig. 9. Removal fractions of inclusions on top surface of mold. sions in the solidified shell.

\subsection{Transport of Inclusions from Slag Entrainment}

According to the earlier results in the present study, some inclusions contain $\mathrm{K}$ and $\mathrm{Na}$ which are the chemical elements in mold slag. Besides, the level fluctuation is violent. Therefore, mold slag entrainment is most likely to appear in CSP mold. It is reported that in CSP mold studied in the present work, the mold slag entrainment is mainly caused by high velocity flow that shears slag from the top surface, and the specific entrainment positions are shown in reference. ${ }^{17)}$ In order to quantitatively investigate the transport of these inclusions, three groups of particles with sizes of $100 \mu \mathrm{m}$, $250 \mu \mathrm{m}$ and $400 \mu \mathrm{m}$, and with the density of $2700 \mathrm{~kg} / \mathrm{m}^{3}$ are taken into account. They are injected into the transi-

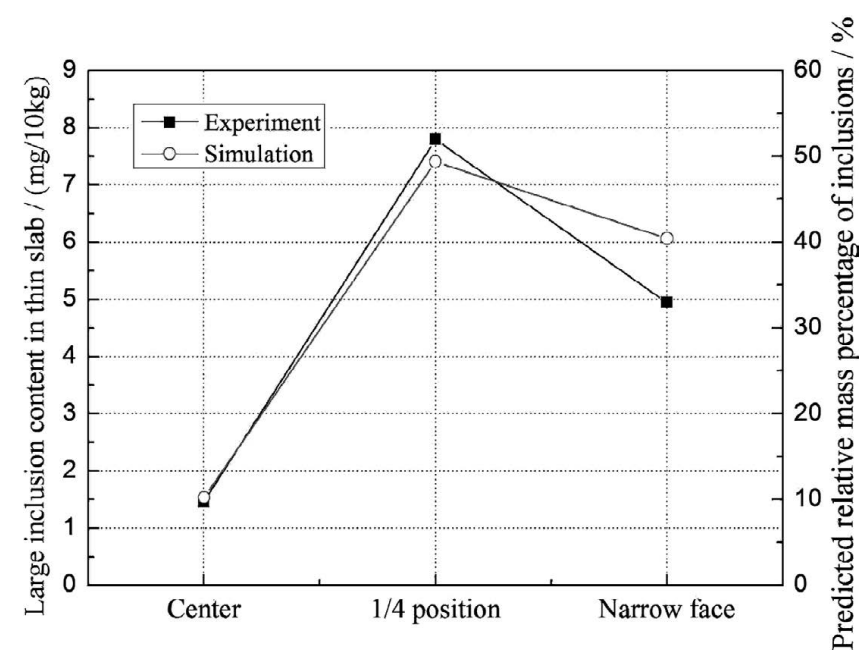

Fig. 11. Distribution of inclusion $(100 \mu \mathrm{m})$ content along the slab width direction.

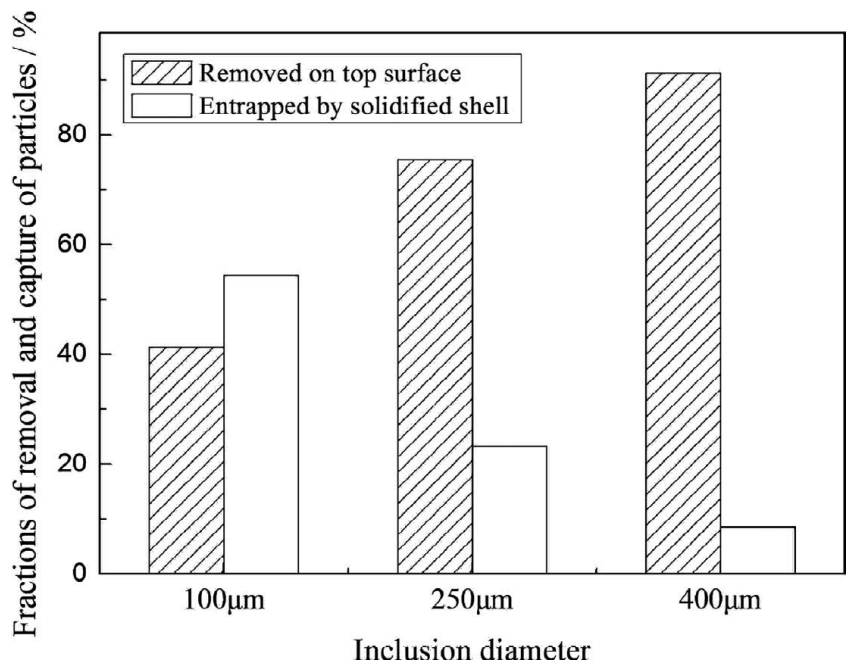

Fig. 12. Fractions of removal and capture of slag particles.

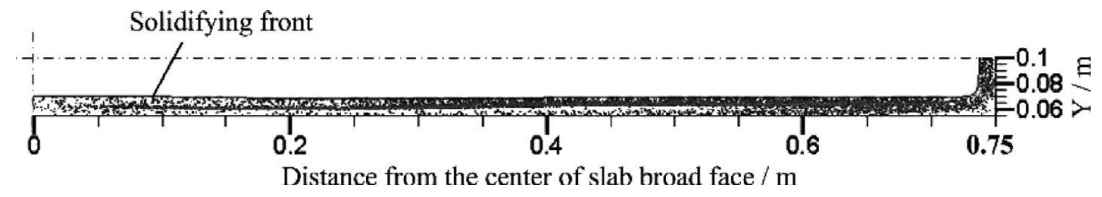

Fig. 10. Predicted distribution of $100-\mu \mathrm{m}$ inclusions within the solidified shell at the domain exit $(\mathrm{z}=2.1 \mathrm{~m})$. 


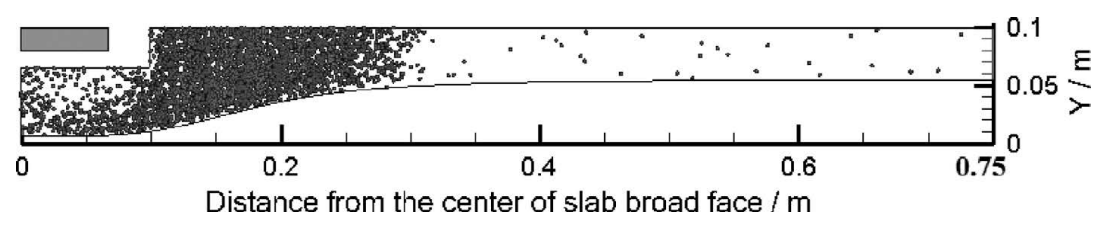

Fig. 13. Predicted final removal positions of $250-\mu \mathrm{m}$ inclusions on the top surface $(\mathrm{z}=0.1 \mathrm{~m})$.

tion zone from funnel to parallel shape $10 \mathrm{~mm}$ below the meniscus, where such slag entrainment most likely occurs. ${ }^{17)}$

Figure 12 presents the fractions of removal and capture of slag particles. The removal fraction increases greatly with particle diameter increasing, whereas the capture fraction is the other way around. More than $91 \%$ of $400-\mu \mathrm{m}$ particles are removed. However, the removal fraction drops to $41 \%$ for $100-\mu \mathrm{m}$ slag particles. Approximately $23 \%$ of $250-\mu \mathrm{m}$ inclusions are entrapped by solidified shell, though a small quantity but detrimental to slab quality. Hence, it is very important to optimize the flow pattern to reduce slag entrainment. Moreover, it should be focused on controlling the flow at the top surface to avoid the entrainment of new slag particles rather than attempting to enhance the removal of inclusions which enter the mold through the SEN.

The predicted removal positions of $250-\mu \mathrm{m}$ inclusions on the top surface are shown in Fig. 13. It is obvious that the removed slag inclusions gather within the funnel zone nearby the SEN. This is related to the slag entrainment position and the horizontal flow below the top surface. The slag droplets would move with the molten steel towards the SEN once mold slag is entrained into the mold. Besides, these large inclusions can easily float up owing to the big buoyancy force. As a result, most of them float to the top in the funnel zone.

\section{Conclusions}

Based on the experimental investigation of large inclusions in thin slab, a 3D analysis of the coupled fluid flow, solidification and inclusion behavior in CSP mold is performed. The following conclusions can be summarized:

(1) Inclusion measurements indicate that some large inclusions may be induced from mold slag entrainment and large inclusions accumulate at the position of 1/4 slab width.

(2) Most of the inclusions injected through SEN are captured by the solidifying shell in the funnel region nearby the parallel part of the mold, which may result in the accu- mulation of inclusions in this region. The removal fraction is less than $4 \%$. Both the experiment and simulation results indicate that large inclusions are mainly concentrated at the position of $1 / 4$ slab width, which may cause the formation of longitudinal cracks.

(3) Inclusions entrained from the liquid mold slag are easy to be removed. Over $75 \%$ of the $250-\mu \mathrm{m}$ to $400-\mu \mathrm{m}$ slag droplets return to the slag layer.

\section{Acknowledgements}

The authors would like to express their gratitude for the financial support by the National Natural Science Fund of China (No.51074023).

\section{REFERENCES}

1) L. C. Hibbeler, B. G. Thomas, B. Santillana, A. Hamoen and A. Kamperman: La Metallurgia Italiana, 2 (2009), 29.

2) A. Ramacciotti: Steel Res., 10 (1988), 438.

3) Y. H. Sun, Y. J. Ni, H. T. Wang, Z. B. Xu and K. K. Cai: Int. J. Min. Met. Mater., 17 (2010), 159.

4) X. F. Zhang, Q. Liu, L. S. Zhang, C. P. Nie and K. Dou: AISTech 2014 Proc., AIST, Warrendale, PA, (2014), 1901.

5) X. Y. Feng, T. S. Yang, S. Y. Zhang and X. Z. Han: Physical Testing and Chemical Analysis Part A: Physical Testing, 40 (2004), 569.

6) L. F. Zhang and B. G. Thomas: XXIV National Steelmaking Symp., The Morelia Institute of Technology, Morelia, (2003), 138.

7) L. F. Zhang, Y. F. Wang and X. J. Zuo: Metall. Mater. Trans. B, 39B (2008), 534.

8) Y. F. Wang and L. F. Zhang: Metall. Mater. Trans. B, 42 (2011), 1319.

9) L. F. Zhang, J. Aoki and B. G. Thomas: Metall. Mater. Trans. B, 37B (2006), 361.

10) Q. Yuan, B. G. Thomas and S. P. Vanka: Metall. Mater. Trans. B, 35B (2004), 703.

11) B. G. Thomas, Q. Yuan, S. Mahmood, R. Liu and R. Chaudhary: Metall. Mater. Trans. B, 45B (2014), 22.

12) Y. Miki, H. Ohno, Y. Kishimoto and S. Tanaka: Tetsu-to-Hagané, 97 (2011), 423.

13) M. R. Aboutalebi, M. Hasan and R. I. L. Guthrie: Metall. Mater. Trans. B, 26B (1995), 731.

14) Z. Q. Liu, L. M. Li, B. K. Li and M. F. Jiang: JOM, 66 (2014), 1184

15) E. Torres-Alonso, R. D. Morales, L. G. Demedices, A. Najera, J. Palafox-Ramos and P. Ramirez-Lopez: ISIJ Int., 47 (2007), 679.

16) L. F. Zhang, S. B. Yang, K. K. Cai, J. Y. Li, X. G. Wan and B. G. Thomas: Metall. Mater. Trans. B, 38B (2007), 63.

17) X. H. Wang, X. H. Wang, J. M. Zhang, W. J. Wang, Y. Z. Chai and B. X. Hong: J. Univ. Sci. Technol. Beijing, 31 (2009), 764. 